\title{
JUVENTUDE, ULTRAMONTANISMO E EDUCAÇÃO CATÓLICA
}

\author{
Youth, ultramontanism and Catholic education
}

\author{
Roseli Boschilia*
}

\begin{abstract}
RESUMO
A partir da época moderna a Igreja católica irá apostar na juventude como a camada social capaz de viabilizar o projeto reformista e, desse modo, a educação constituirá um mecanismo eficiente para frear os avanços da modernidade. Atenta às transformações ocasionadas pelo contexto de consolidação do Estado Moderno, a Igreja católica procurará acompanhar o processo de mudanças bastante visíveis ocorridos no espaço cultural e social e cujos reflexos terão desdobramentos na estrutura escolar, nas práticas de sociabilidade e, sobretudo, no papel ocupado pelo jovem na sociedade moderna. Sendo assim, esse artigo procura refletir sobre a política implementada pela Igreja católica ultramontana na construção de um discurso em que o jovem aparece como o depositário das esperanças de sedimentação de valores e costumes, elegendo-o como um dos elementos capazes de evitar as mudanças e manter a tradição.
\end{abstract}

Palavras-chave: ultramontanismo; juventude e educação católica.

\begin{abstract}
Starting at the modern age the Catholic Church begins to bet on the youth as the social segment capable of making the reformist project become viable and, this way, the education would turn into an effective mechanism to stop modernity's advancements. Aware of the transformations caused by context of the Modern State's consolidation, the Catholic Church will try to keep pace with the visible changing process that happened at the cultural and social space, whose reflections will unfold in the educational structure, in the social practices and, above

* Doutora em História do Brasil pela Universidade Federal do Paraná. Professora adjunta do Curso de História da Universidade Tuiuti do Paraná.
\end{abstract}




\begin{abstract}
all, in the role played by the young in modern society. In that regard, this article would try to reflect about the policies implemented by the Ultramontane Catholic Church in the construction of a discourse in which the young appears as a depository of the hopes in the sedimentation of values and habits, electing them as the elements capable of preventing the changes and keeping the tradition.
\end{abstract}

Key-words: ultramontanism; youth and Catholic education.

Qualquer reflexão acerca da juventude exige do pesquisador a apropriação de um referencial teórico que possibilite pensar essa categoria de forma relacional. Isso se faz necessário na medida que o jovem insere-se numa camada intermediária entre o mundo infantil e $\mathrm{o}$ adulto. ${ }^{1}$ Pela dificuldade em situá-lo a partir de uma simples dicotomização, tal como ocorre, por exemplo, na análise de outras categorias sociais, como a de gênero, de classe social, de raça, de credo religioso ou de opção política, demorou muito tempo para que o jovem, enquanto objeto, merecesse um tratamento particular. Embora, a rigor, até o início da era industrial não se possa conceituar a juventude enquanto uma categoria social definida, é importante lembrar que, desde a Idade Antiga, essa camada sempre se singularizou como um conjunto distinto de pessoas, sujeito a comportamentos claramente identificados. $^{2}$

Desse modo, longe de considerar a história da juventude como um processo linear e evolutivo, ou tampouco tentar restringi-la às condições materiais ou de classe social, pode-se perceber que em diferentes sociedades essa fase é caracterizada pela sucessão de ritos que marcam a saída da infância e a entrada na vida adulta. A existência dos ritos de passagem evidencia essa etapa da vida como um momento de transição em que o processo de socialização do indivíduo se consolida. Esse momento de transformação, que ocorre tanto no plano individual quanto social, será definitivo para a escolha dos papéis sociais a serem desempenhados na vida adulta.

1 PASTOUREAU, Michel. Os emblemas da juventude: atributos e representações dos jovens na Idade Medieval. In: LEVI, Giovanni; SCHMITT, Jean-Claude (Orgs.). História dos jovens: da antiguidade à era moderna. São Paulo: Cia. das Letras, 1996. p. 250.

2 SCHNAPP, Alain. A imagem dos jovens na cidade grega. In: LEVI, Giovanni; SCHMITT, Jean-Claude (Orgs.). História dos jovens: da antiguidade à era moderna. São Paulo: Cia. das Letras, 1996. p. 35. 
Durante o período medieval, graças à utilização de uma doutrina calcada no castigo e no medo do inferno, a Igreja Católica garantiu o monopólio político e espiritual sobre a sociedade, impondo um modelo em que a inserção do indivíduo no espaço social deveria obedecer aos critérios morais. Assim, construiu-se um modelo de conduta em que a idéia do mal e do pecado estava presente em todos os comportamentos ou atitudes do espaço profano que fugissem ao controle da Igreja ou evidenciassem a possibilidade de transgressão do código moral vigente. Nessa época, passou a existir uma representação negativa da juventude, sendo essa fase da vida associada ao tempo dos apetites e de seus excessos. Havia o consenso que "por falta de freio e de governo, a juventude entrega[va]-se ao mal”, e, por isso, era necessário impor uma socialização para controlar as suas pulsões. ${ }^{3}$ Nesse sentido, as práticas sociais (festas, jogos, torneios, apresentações teatrais etc), menos do que divertimento, serviam para fortalecer os comportamentos coletivos garantindo a manutenção de um código moral. ${ }^{4}$

Essa imagem perigosa dos jovens, ligada aos excessos, às transgressões e à licenciosidade, será mantida até o final da Idade Média, onde cada sociedade alimentará uma imagem particular de sua juventude, estabelecendo códigos, atributos e procedimentos próprios para distinguir a fase transitória entre o início da puberdade e a vida adulta. ${ }^{5}$

A atmosfera de controle e cerceamento imposta à juventude medieval pode ser evidenciada até mesmo na ausência de imagens que representassem essa camada. Com exceção dos jovens santos, sobre os quais se produziu uma profusão de documentos iconográficos, os historiadores dispõem de parco material para estudar a juventude desse período. Segundo Pastoureau, ${ }^{6}$ os estudos iconográficos sobre a Idade Média mostram que o fato do jovem ocupar um lugar pequeno na imagem demonstra que o lugar ocupado por ele na sociedade também era restrito.

3 CROUZET-PAVAN, Elizabeth. Uma flor do mal: os jovens na Itália medieval (séculos XIII-XV). In: LEVI, Giovanni; SCHMITT, Jean-Claude (Orgs.). História dos jovens: da antiguidade à era moderna. São Paulo: Cia. das Letras, 1996. p. 191.

4 Ibid., p. 217.

5 No entanto, vale lembrar que, embora a vinculação da juventude com os perigos do pecado seja a marca da sociedade medieval, a concepção de juventude presente no imaginário social durante esse período não deve ser vista como uniforme ou imóvel (PASTOUREAU, op. cit., p. 245.).

6 Ibid., p. 252. 
Todavia, foi no bojo das transformações trazidas pela modernidade, que a juventude surgiu como uma nova categoria social, distinta daquela ocupada em épocas anteriores. ${ }^{7}$ A dilatação das bases territoriais, a partir da época moderna, levou os jovens a extrapolarem os limites da aldeia e a estabelecerem novas formas de sociabilidade. ${ }^{8}$ De acordo com a historiadora Natalie Davis - dedicada à análise de comportamentos e atitudes populares a partir da antropologia simbólica -, no início da Idade Moderna a cultura juvenil caracteriza-se como "uma cultura do tipo informal, que vai se constituindo essencialmente por meio de uma prática ritual”. ${ }^{9}$

A configuração desse novo contexto implicou a necessidade de homogeneização e controle social. Surgiram novas formas de socialização e progressivamente os espaços institucionais passaram a adotar sistemas mais rigorosos de classificação e controle.

Nesse sentido, a disciplina foi introduzida no espaço escolar com o propósito de submeter o aluno a um controle cada vez mais estrito. Da mesma maneira, a distribuição por faixa etária passou a obedecer critérios mais precisos. Contrapondo-se à pedagogia humanista, que não fazia distinção entre a criança e o homem, o processo de diferenciação da massa escolar, iniciado no final do século XV, e sobretudo a partir do século XVI, com o objetivo de adaptar o ensino ao nível dos alunos, indicava a preocupação com as particularidades da infância e da juventude.

O esforço empreendido para produzir o homem esclarecido, sobretudo durante o século XVIII, fez com que as idades fossem reinventadas e a passagem da infância à idade adulta passasse a ser ritmada pela educação e pela instrução. ${ }^{10}$ Enquadrada e classificada enquanto categoria social, a juventude passou a ser alvo de preocupações de pensadores e pedagogos, ${ }^{11}$ e a sua vinculação às idéias de transitoriedade, mudança e instabilidade

7 PASTOUREAU, op. cit., p. 245-263.

8 LEVI, Giovanni; SCHMITT, Jean-Claude. (Orgs.) História dos jovens: da antiguidade à era moderna. São Paulo: Cia. das Letras, 1996. p. 16.

9 Conforme SCHINDLER, Norbert. Os tutores da desordem: rituais da cultura juvenil nos primórdios da Era Moderna. In: LEVI, Giovanni; SCHMITT, Jean-Claude. (Orgs.) História dos jovens: da antiguidade à era moderna. São Paulo: Cia. das Letras, 1996. p. 273.

10 CARON, Jean-Claude. Os jovens na escola: alunos de colégios e liceus na França e na Europa (fim do séc. XVIII - fim do século XIX). In: LEVI, Giovanni; SCHMITT, Jean-Claude. (Orgs.) História dos jovens: a época contemporânea. São Paulo: Cia. das Letras, 1996. p. 141.

11 ARIÈS, Philippe. História social da criança e da família. Rio de Janeiro: Guanabara; Koogan, 1981. p. 231. 
contribuiu para que a categoria passasse a ser concebida como metáfora das mudanças sociais, sendo identificada por diferentes correntes do pensamento como portadora de esperanças e ameaças sociais latentes. ${ }^{12}$

Desse modo, atenta às transformações ocasionadas pelo contexto de consolidação do Estado Moderno, a Igreja católica passou a vislumbrar na educação do jovem a possibilidade de minimizar os danos sofridos pela instituição com as mudanças ocorridas no espaço cultural e social. A declaração do Padre Mutius Viterlichi, Geral da Companhia de Jesus, que via na educação do jovem o principal meio que a Divina Providência concedera aos jesuítas para reformar a humanidade, ${ }^{13}$ além de reiterar a importância dada à educação pelo Concílio de Trento, evidenciava claramente a intenção da Igreja de escolher a juventude como a camada social capaz de viabilizar o projeto reformista e a educação como um mecanismo eficiente para frear os avanços da modernidade.

Vale lembrar que a experiência acumulada no campo educacional, desde a época dos jesuítas, dava à Igreja argumentos para construir um discurso competente, colocando-a numa posição privilegiada na defesa de seus interesses nessa área. Entretanto, para a viabilização de um projeto moral, através da ação educacional, era preciso realizar um trabalho efetivo com aqueles agentes mais vulneráveis às idéias modernas. O monopólio do poder dependia de uma determinada visão de mundo, cujos princípios deveriam ser impostos a um conjunto de indivíduos e, para atingir esse objetivo, era preciso estabelecer um consenso quanto à unidade e à identidade desse grupo. ${ }^{14}$ Sabidamente esse grupo social era a família e, entre seus membros, os jovens eram os mais suscetíveis às inovações trazidas pela modernidade.

A juventude era considerada uma idade perigosa, justamente porque nessa fase, marcada pela desordem, ausência de uma organização reconhecida e de uma hierarquia clara, o indivíduo vivia um período de transformação em busca de sua individualidade. Para manter a ordem social, política e religiosa os jovens precisavam ser contidos e, nesse sentido, fa-

12 SCHINDLER, op. cit., p. 267.

13 NUNES, Maria Thétis. Ensino secundário e sociedade brasileira. 2. ed. São Cristóvão (SE): UFS, 1999. p. 26.

14 BOURDIEU, P. A economia das trocas linguísticas: o que falar quer dizer. São Paulo: Edusp, 1996. p. 108. 
zia-se necessário a adoção de medidas de controle que fossem capazes de assegurar um comportamento social pautado em princípios éticos e religiosos. O descontrole, a excitação e o rebuliço, características marcantes nessa idade, precisavam ser substituídos pelo domínio de si e pela sujeição moral.

Nesse período, a juventude ocidental já havia se transformado num corpo constituído, ganhando status de categoria social particular, com demarcações para o início e o término dessa etapa transitória entre a infância e a vida adulta, claramente delineados. Aproveitando esse momento crítico (da juventude), definido como “de latência (...) em busca de uma expressão autônoma”, ${ }^{15}$ a Igreja procurará utilizar os liceus e as universidades, bastiões da juventude burguesa, para inserir o jovem num sistema "adequado" às expectativas do Estado e da sociedade burguesa.

Dessa forma, as novas práticas pedagógicas, implantadas no final do século XVIII, procuravam evidenciar, cada vez mais, o papel preponderante da educação na modelagem do homem e, a partir daí, o ensino secundário, mais do que ensinar, tinha a obrigação de educar moralmente o futuro adulto. ${ }^{16}$ Nessa perspectiva, os educadores deveriam conciliar uma instrução de qualidade, sem detrimento dos aspectos ligados ao domínio da moral e da religião. ${ }^{17}$

As preocupações em diferenciar os processos de crescimento, formação e educação tiveram como resultado a passagem da educação familiar para o âmbito da escola. ${ }^{18}$ Esse processo de substituição da família pela

15 PERROT, Michelle. A juventude operária, da oficina à fábrica. In: LEVI, Giovanni; SCHMITT, Jean-Claude (Orgs.). História dos jovens: a época contemporânea. São Paulo: Cia. das Letras, 1996. p. 84.

16 CARON, op. cit., p. 138-139.

17 A tentativa de propor métodos mais adequados para a aprendizagem levou o alemão Froebel, um seguidor de Rousseau e de Pestalozzi, a desenvolver um método particular que procurasse favorecer o desenvolvimento da criança por meio de exercícios, jogos e cantigas. Nessa mesma perspectiva, o Abade Gaultier, baseando-se nas idéias do francês Rollin, desenvolveu, em 1780, o método recreativo, cujo princípio consistia em tornar o ensino mais agradável, por meio da emulação.

18 Não se pode esquecer também que as transformações ocorridas durante o processo de constituição do Estado Moderno provocaram mudanças significativas no âmbito da família. A passagem do modelo da família tradicional (extensa) para família moderna (nuclear) colocava em risco a preservação dos valores morais que antes eram garantidos pelo estreito convívio de diversas gerações no mesmo espaço doméstico. Com o surgimento da família nuclear, a possibilidade de uma ruptura na transmissão desses valores tornava-se cada vez maior. (SHORTER, Edward. Naissance de la famille moderne XVIII-XXe siècle. Paris: Editións du Seuil, 1977). 
escola, consolidado na passagem do século XVIII para o XIX, transformou o colégio numa instituição essencial à sociedade, abrindo-se para os leigos, nobres, burgueses e também para famílias mais populares. ${ }^{19}$

A abertura dos estabelecimentos de ensino à população em geral também era uma resposta aos novos tempos, descortinados pela Revolução Industrial, que evidenciavam a necessidade de instituições dirigidas a outras camadas da população que não apenas à elite. A Igreja, no entanto, já evidenciava sua preocupação com as camadas mais pobres, desde o século XVII. Visando garantir a ordem e a moralidade pública e preparar trabalhadores produtivos para a nova sociedade que se instituía, foi fundada no final do século XVII, por João Batista de La Salle, o Instituto dos Frades das Escolas Cristãs. Antes disso, os lazaristas já haviam fundado a Sociedade dos Padres da Missão, com o objetivo de oferecer ensino especialmente às classes populares. Nesse rastro, surgiram a partir do século XIX, outras congregações como a dos maristas ${ }^{20}$ e a dos salesianos ${ }^{21}$ que, ao contrário dos jesuítas, estavam mais preocupadas com "o grosso da tropa” do que com os "vanguardeiros". ${ }^{22}$

Assim, durante a primeira metade do século XIX, o desenvolvimento gradativo das congregações religiosas possibilitou à Igreja a penetração no ensino público e privado, favorecendo a atuação dos

19 ARIÈS, op. cit., p. 171-173.

20 Fundada por Marcelino Champagnat, a congregação Marista surgiu na França, em 1817, no bojo do movimento de retorno que caracterizou o período posterior à Revolução Francesa. Apoiando- se no modelo disciplinar dos jesuítas e nas propostas formuladas por La Salle, na obra A conduite des écoles chrétiennes, os maristas procuraram trabalhar junto às populações camponesas no interior da França.

21 A congregação de São Francisco Sales foi fundada, em 1859, por São João Bosco. Os salesianos atuaram inicialmente na Itália, buscando preservar os meninos oriundos das classes mais pobres dos riscos da indigência e da corrupção. Para tanto, a congregação criou os oratórios festivos, que eram locais destinados a abrigar jovens marginalizados e oferecer instrução religiosa, bem como as escolas profissionalizantes, cujo principal objetivo era a educação para o trabalho. Sobre o assunto ver NEGRÃO, Ana Maria Melo. Educar para a cidadania através de valores católicos: Liceu Salesiano Nossa Senhora Auxiliadora. In: NASCIMENTO, Terezinha A. Quaiotti do (Org.). Memórias da Educação: Campinas (18501960). Campinas: Unicamp, 1999. p. 197-243.

22 ANDRADE, Mariza Guerra de. A educação exilada: Colégio do Caraça. Belo Horizonte: Autêntica, 2000. p. 33. 
ultramontanistas. ${ }^{23}$ Também surgiram nesse período, ao lado das congregações masculinas, as primeiras congregações femininas que, mais tarde, voltaram-se à área educacional, como a das Irmãs de São José de Chambery ${ }^{24}$ e as Filhas de Caridade de São Vicente de Paulo.

Os modelos disciplinares adotados pelas congregações católicas, além de estarem associados a uma nova concepção de educação, visavam garantir a reprodução de modelos de conduta e, nesse sentido, tinham o respaldo das famílias, também interessadas num controle mais efetivo sobre os filhos. À medida que a criança e o adolescente passavam cada vez mais tempo na escola, ${ }^{25}$ cabia à família escolher uma boa instituição para que a educação ministrada em sala de aula fosse estendida para fora dos muros escolares, de forma a garantir que as crianças e os adolescentes fossem preservados das rudezas e da imoralidade do mundo dos adultos.

Todavia, apesar do esforço da Igreja em estender a educação para outras camadas da população, de modo geral o sistema educacional, sobretudo no nível secundário, continuava restrito a uma pequena camada, constituindo-se num dos requisitos básicos para que alguém tivesse o status de classe média reconhecido, enquanto a educação superior havia se transformado no passaporte que garantia o acesso à alta classe média e outras elites. $^{26}$

23 Também conhecido como romanização ou reforma, o movimento ultramontano, de inspiração clerical e hierárquica, teve como proposta um projeto de reeuropeização do catolicismo, marcado pela centralização institucional na figura do Papa e, enquanto orientação política, procurou garantir a independência da Igreja contra as pretensões regalistas dos governos. De acordo com os ultramontanos, a salvação da humanidade dependeria da recristianização do mundo e essa tarefa deveria ser assumida pela Igreja, portadora da Verdade, conforme definição do Concílio de Trento. (MANOEL, Ivan. Igreja e educação feminina (1859-1919): uma face do conservadorismo. São Paulo: Unesp, 1996. p. 42). No Brasil, a penetração do catolicismo ultramontano teve início na segunda década do século XIX, com a vinda de alguns padres lazaristas, cujo objetivo era o de promover a expansão das missões populares e oferecer educação e formação em colégios e seminários como os de Caraça, Campo Belo e Mariana (WERNET, Augustin. A Igreja Paulista no século XIX: a reforma de D. Antônio Joaquim de Melo (1851-1861). São Paulo: Ática, 1987. p. 96).

24 Fundada pelo jesuíta, Pe. João Pedro Médaille, a congregação das Irmãs de São José teve sua origem em meados do século XVII, na França. A partir do início do século XIX, passou a trabalhar também na área educacional, atuando no Brasil desde 1959.

25 Ao mesmo tempo que cresceu o número de crianças e adolescentes que passaram a freqüentar a escola, também aumentou o tempo de permanência deles no espaço escolar. Embora a oferta do ensino secundário continuasse restrita às camadas mais privilegiadas, no final do século XVIII já era comum os alunos permanecerem na escola por um período de quatro ou cinco anos.

26 HOBSBAWM, Eric. A produção em massa de tradições: Europa, 1870 a 1914. In: HOBSBAWM, Eric; RANGER, Terence (Orgs.). A invenção das tradições. Rio de Janeiro: Paz e Terra, 1984. p. 301. 
Dando continuidade ao seu projeto educacional, uma das preocupações da Igreja, durante o século XIX, foi mostrar aos governantes que a ausência de uma educação cristã teria como consequiência a falta de disciplina e esta poderia ser perigosa para o Estado. Nessa perspectiva, a defesa da educação da juventude, dentro dos princípios católicos, teve papel fundamental nas reflexões do Papa Leão XIII (1873-1903). Em suas palavras, "os jovens sem o hábito de respeitar a Deus, não poderão suportar disciplina alguma de vida honesta e acostumados a não negar jamais coisa alguma às suas tendências, facilmente serão induzidos a perturbar os estados". ${ }^{27}$ Desse modo, Leão XIII defendia a idéia de que o bom cristão seria um bom cidadão e para atingir esse objetivo era imprescindível a aliança entre a fé e a razão. Do seu ponto de vista, a responsabilidade pela educação da juventude cabia à Igreja e ao Estado, cabendo aos pais, no entanto, "assegurar de um modo absoluto que lhes fique o poder de educar cristãmente os filhos, como é da sua obrigação, e principalmente o poder de negá-los àquelas escolas em que há perigo de beberem o triste veneno da impiedade”. ${ }^{28}$

Desse modo, para reconquistar o espaço do saber e do poder, a Igreja procurava construir um discurso calcado em princípios éticos e morais, atrelando a necessidade de disciplina como forma segura para a manutenção da ordem social. Buscou a família como parceira nesse processo, enfatizando a sua responsabilidade pela escolha da educação formal dos filhos. Tomando cuidado para não interferir no espaço político do Estado, a Igreja procurava colocar-se como a única instituição capaz de implantar um projeto moral adequado para a manutenção da ordem vigente e construiu um discurso em que o jovem aparece como o depositário das esperanças de sedimentação de valores e costumes, elegendo-o como um dos elementos capazes de evitar as mudanças e manter a tradição.

Como na nossa época a fé cristã está diariamente exposta às manobras e astúcias de uma falsa sabedoria, cumpre que todos os jovens, e particularmente aqueles cuja educação é a esperança da Igreja, sejam nutridos de uma doutrina substancial e forte, a fim de que, cheios de vigor e revestidos

27 Conforme PIO XI, Papa. Encíclica Divini Illius Magistri. 1929. Sobre a educação cristã da juventude. São Paulo: Edições Paulinas, 1965. p. 13.

28 Ibid., p. 18. 
de uma armadura completa, cedo se habituem a defender a religião com denodo e sabedoria, "prontos”, consoante o aviso do apóstolo, "a dar a quem quer que a peça a razão da esperança que está em nós”. ${ }^{29}$

Diante desse quadro, um dos projetos de ação política da Igreja ultramontana foi estimular, em muitos países europeus, o renascimento e a criação de várias ordens e congregações religiosas ${ }^{30}$ voltadas para a educação e assistência das camadas mais empobrecidas. Assim, procurando fazer frente às demandas da emergente sociedade industrial, carente de cidadãos preparados para o mundo do trabalho, surgiram congregações religiosas masculinas e femininas de diversas nacionalidades voltadas especificamente à educação da juventude.

Atentas às demandas educacionais provocadas por uma clientela cada vez mais numerosa e exigente, as congregações católicas procuraram se adequar ao contexto socioeconômico do século XIX, adaptando seu método às novas exigências sociais. Dessa forma, aliando princípios católicos aos ideais positivistas de ordem e progresso, que pautavam o ensino laico, muitas congregações se propunham a preparar os jovens, adequadamente, para inseri-los na sociedade do trabalho, sem, contudo, deixar de lado o principal objetivo da instituição, que era o de manter e disseminar o catolicismo dentro dos moldes tradicionais pregados pela doutrina ultramontana.

A partir dessa perspectiva, os estabelecimentos católicos procuraram consolidar um projeto educacional que objetivava a formação de cidadãos cristãos, disciplinados e virtuosos que, além de incorporarem as noções aprendidas no espaço escolar, fossem capazes de promover a reprodução desse modelo no espaço social. Para tanto, era necessário oferecer uma educação completa sedimentada na "obediência" e na "disciplina", consideradas como meios eficazes para a formação da vontade. Dentro da edu-

29 LEÃO XIII, Papa. Encíclica Aeterni Patris. 1879. Sobre a filosofia cristã. Rio de Janeiro: Vozes, 1956. p. 24.

30 Muitas ordens e congregações que haviam sido extintas durante a Revolução Francesa ressurgiram durante a primeira metade do século XIX, mas somente no início do século XX a Igreja conservadora atingiu seus objetivos. AUBERT, Roger; HAJJAR, Joseph. A Igreja na sociedade liberal e no mundo moderno. Petrópolis: Vozes, 1976. v. 1 e 3. p. 109. 
cação moral, a vontade deveria ser construída, da mesma maneira que se “constrói um músculo”, visando produzir atos repetidos da virtude desejada, como, por exemplo, o amor ao trabalho. Nesse sentido, a regularidade das atividades diárias cumpria importante papel, não somente no sentido de facilitar a internalização de normas e regras, mas também como uma fórmula de controle e dominação, uma economia de poder que visava introjetar nos alunos o hábito do trabalho.

Preocupados com uma educação completa, que incidisse sobre o corpo, o intelecto e a alma do aluno, os colégios católicos faziam uso de dispositivos de controle que visavam não apenas levar o estudante a usar o tempo e o espaço de uma forma particular, mas exercitar o autocontrole, ou seja, entre as diversas tecnologias de controle utilizadas pela escola, o autodisciplinamento visava exercitar o domínio sobre o próprio corpo como uma das maneiras de aprender a administrar a vontade e governar a si mesmo. ${ }^{31}$

Para alcançar esses objetivos era fundamental que o aluno permanecesse o maior tempo possível no estabelecimento de ensino, protegido das ameaças do mundo externo. Nesse sentido, uma das estratégias utilizadas era dispor de amplos espaços ao redor dos edifícios escolares como um recurso pedagógico que levasse o indivíduo a aprender a mover-se no grande espaço, de forma organizada e disciplinada. ${ }^{32}$ As sólidas paredes externas, muito mais do que estabelecer limites entre o mundo sagrado e o profano, tinham como atribuição demarcar as dicotomias entre o interno e o externo, o fechado e o aberto, o proibido e o permitido, procurando distinguir seus alunos dos outros, daqueles que estavam fora de seus muros. ${ }^{33} \mathrm{~A}$ escola passava a constituir, assim, a um só tempo, um espaço e um lugar no qual o aluno, além de aprender a orientar-se e a mover-se na vida em sociedade, aprendia, sobretudo, a conhecer o seu lugar na estrutura social e o papel que lhe foi destinado. ${ }^{34}$ Nessa perspectiva, o espaço adquiria uma dimensão

31 LOURO, Guacira Lopes. Pedagogias da sexualidade. In: LOURO, G. L. (Org.). O corpo educado: pedagogias da sexualidade. 2. ed. Belo Horizonte: Autêntica, 2000. p. 22.

32 FOUCAULT, Michel. Vigiar e punir: história da violência nas prisões. 8. ed. Petrópolis (RJ): Vozes, 1987. p. 136.

33 LOURO, Guacira Lopes. Gênero, sexualidade e educação: uma perspectiva pós-estruturalista. 3. ed. Petrópolis: Vozes, 1999. p. 91.

34 VIÑAO FRAGO, Antonio. Del espacio escolar y la escuela como lugar: propuestas y cuestiones. Historia de la Educación, v. 12-13, p. 17-94, 1993/1994. 
educativa, podendo ser visto como um componente da arquitetura escolar que encerraria "uma espécie de discurso que institui em sua materialidade um sistema de valores, como os de ordem, disciplina e vigilância, marcos para a aprendizagem sensorial e motora e toda uma semiologia que cobre diferentes símbolos estéticos, culturais e ainda ideológicos”. ${ }^{35}$ Ou seja, os espaços constituíam-se em um importante recurso didático, cujo objetivo primordial era o de produzir novas categorias de pensamento e novos sistemas de representação que se traduziriam em formas diferenciadas de organização social. ${ }^{36}$

Além da utilização do espaço como um recurso pedagógico, outra estratégia utilizada pelos colégios católicos era a separação do alunato, de acordo com o perfil da clientela, em estabelecimentos distintos. O caráter homogâmico do grupo, além de possibilitar uma maior eficácia nos métodos de vigilância, evitava a utilização de outros mecanismos de controle e disciplina, que eram necessários em estabelecimentos onde alunos internos, externos e seminaristas, ao conviverem nos mesmos espaços escolares, eram constantemente vigiados e impedidos de qualquer contato.

Outro fator explicativo para a divisão da clientela escolar também pode ser atribuído ao desejo das congregações católicas de atender às exigências de determinados grupos sociais, ou seja, de famílias às quais interessava manter os filhos num espaço de relações sociais homogâmicas. Conforme observa Hobsbawm, ${ }^{37}$ na Inglaterra do final do século XIX e início do XX, esse era, por exemplo, um dos critérios adotados pela elite e pela burguesia ascendente para a escolha do colégio de seus filhos.

Embora a separação dos estudantes em estabelecimentos distintos minimizasse os problemas causados pelo contato entre internos e externos, nos internatos masculinos a convivência diária e a proximidade dos alunos em áreas comuns (refeitórios, dormitórios e sanitários), onde as possibilidades de vigilância eram menores, exigiam um maior rigor na delimitação dos territórios ocupados por crianças, adolescentes e jovens. Nos institutos dirigidos pelos Maristas, os internos eram separados fisicamente em dois

35 ESCOLANO, Agustin. La arquitetura como programa. Espacio-escuela y curriculum. Historia de la Educación, v. 12-13, p. 97-120, 1993-1994.

36 VARELA, Julia. Categorias espaço-temporais e socialização escolar: do individualismo ao narcisismo. In: COSTA, Marisa Vorraber. Escola básica na virada do século: cultura, política e currículo. 2. ed. São Paulo: Cortez, 2000. p. 73. 1998. p. 253.

37 HOBSBAWM, Eric. A era dos impérios (1875-1914). 3. ed. Rio de Janeiro: Paz e Terra, 
grupos, de acordo com a faixa etária. No Juvenato Champagnat, em Curitiba, por exemplo, além de ocuparem alas distintas no interior do prédio, crianças e adolescentes eram separados em pátios localizados em espaços radicalmente opostos da grande propriedade. Assim, o isolamento visual, nos momentos de atividade física e lazer, obtido pelo próprio edifício, garantia que os alunos jamais se encontrassem, nem mesmo no horário da missa.

A preocupação em reforçar a vigilância nesses espaços está evidenciada no Guia das Escolas Maristas, ao trazer recomendações explícitas sobre os cuidados a serem tomados nos dormitórios - que deveriam permanecer fechados durante o dia - e nos banheiros, onde era imprescindível a presença do irmão responsável durante o horário de banho coletivo dos grupos. Da mesma forma, a proibição expressa no Guia de que os meninos colocassem as mãos no bolso durante as atividades de recreação ou passeios chama a atenção para a tentativa dos Irmãos de domar os impulsos da sexualidade, procurando manter a "inocência” dos alunos e retardar o máximo possível as descobertas “indesejadas”. Nesse sentido, o mestre também deveria cuidar para que não existissem jamais "relações mais íntimas” ou “familiaridade perigosa” entre os alunos. De acordo com o Guia, “uma união muito estreita entre duas crianças, sobretudo se a diferença de idade for considerável, deverá ser desfeita”. ${ }^{38}$ Uma das medidas recomendadas nesse aspecto era mudar de tempos em tempos os lugares dos alunos, evitando assim a possibilidade de uma amizade mais estreita. Nem mesmo durante as refeições era permitido o contato dos menores com os maiores.

Também era preciso tomar todas as precauções para que os alunos das escolas católicas internalizassem comportamentos adequados ao padrão de masculinidade construído pela sociedade da época. Nesse aspecto, a questão da homossexualidade era um fantasma que deveria ser combatido ferozmente e, por isso, os cuidados com a exposição do corpo eram uma preocupação constante: "Ninguém podia ficar nu no ginásio (...) a camisola intermediava tudo. Punha-se a camisola para tirar a roupa, punha-se a camisola para botar o calção (tomava-se banho de chuveiro usando calção), punha-se a camisola para tirar o calção...”. ${ }^{39}$ O depoimento sobre o cotidiano

38 GUIDE des écoles a l'usage - rédigé d' aprés les regles et les instituction du Vénérable Champagnat. 3. ed. Paris: Libraire Catholique Emmanuel Vitte, 1923. p. 110.

39 MAIA, Newton Freire. In: AZZI, Riolando. História da educação católica no Brasil: contribuição dos Irmãos Maristas. São Paulo: Loyola: SIMAR, 1996/99. 3 v. p. 69-70. 
de um colégio católico, no início da década de 1930, retrata os cuidados tomados pelos Irmãos para impedir que os jovens tivessem qualquer contato, ainda que de forma apenas visível, com os perigos do corpo.

Cercados por duas modalidades distintas de tecnologias de poder (a do corpo e a dos espaços), a ação dos alunos estava, portanto, condicionada a um sistema de imposições previamente definidas, que levavam os diferentes grupos, classificados de acordo com o nível escolar, a manterem relações intergrupais, inscritas num quadro de territorialidade, onde cada grupo acabava constituindo uma configuração social específica, com fronteiras delimitadas. Dessa forma, os alunos eram condicionados a reconhecer o território assinalado, o lugar reconhecido a cada indivíduo, o que correspondia a uma hierarquia social e política materialmente representada no espaço, que deveria ser também reproduzida na sociedade.

Nesse sentido, outra estratégia utilizada pelos colégios católicos para manter os alunos atrelados a uma comunidade de inscrição era incentivar as práticas de sociabilidade que congregassem exclusivamente seus alunos, procurando, dessa maneira, afastá-los dos demais grupos de jovens, principalmente daqueles oriundos das escolas públicas.

Para manter essa separação, as escolas católicas vão procurar criar espaços próprios de sociabilidade, tanto no âmbito interno quanto externo ao colégio, onde os estudantes pudessem desenvolver atividades esportivas, culturais e religiosas que os mantivessem longe do ócio, dos perigos e das tentações que rondavam o espaço urbano.

Além das atividades regulares, alguns eventos, como os jogos católicos, as festas religiosas, excursões, piqueniques, exposições, peças teatrais e apresentações musicais, também tinham o objetivo de minimizar as possibilidades de relacionamento com grupos alheios ao seu universo cultural.

De modo geral, por não serem de caráter obrigatório, essas práticas davam ao estudante a possibilidade de escolha, permitindo que a formação dos grupos internos fosse determinada por interesses individuais ou afinidades eletivas. O maior grau de liberdade dos alunos para selecionar as atividades das quais desejavam participar permite perceber, com maior clareza, como eram engendradas as redes de sociabilidade entre os diferentes grupos e, ao mesmo tempo, como, a partir dessa agregação, era forjada uma identidade específica que distinguia a comunidade formada pelos alunos dos colégios católicos dos jovens em geral. 
Assim, o principal intuito das congregações católicas era o de criar um sistema de pensamento e de condutas singulares que possibilitasse ao aluno católico reconhecer e ser reconhecido, em qualquer situação, como componente de um grupo exclusivo. Ou seja, para designar a identidade coletiva era preciso delimitar o "território" e as suas relações com o meio ambiente, formando imagens dos inimigos e dos amigos, rivais e aliados. ${ }^{40}$ Para a inculcação dessa identidade específica era preciso um esforço no sentido de criar condições para que os alunos permanecessem no colégio o maior tempo possível, evitando dessa forma a convivência mais estreita com indivíduos estranhos ao grupo.

Os estranhos ou outsiders, conforme definição de Norbert Elias, eram, principalmente, os estudantes das escolas públicas e leigas, vistos como companhia a ser evitada devido à formação religiosa inadequada, ou deficitária, recebida nesses estabelecimentos. Quanto aos estudantes de outros colégios católicos, masculinos e femininos, a convivência era aceita, ocorrendo até mesmo parcerias em alguns eventos religiosos e culturais. Sendo assim, a identidade dos alunos católicos era construída em oposição a outros grupos, ${ }^{41}$ tendo como viés principal a prática religiosa e as práticas de sociabilidade.

No Brasil, particularmente, o modelo das escolas católicas encontrou ressonância, na medida em que veio atender aos anseios de determinadas camadas, formadas especialmente por famílias tradicionais ou de descendentes de imigrantes, que, após terem obtido sucesso na área do comércio e da indústria, estavam interessadas em investir na formação superior de seus filhos, direcionando-os para outras atividades - sobretudo as liberais - mais condizentes com o meio social no qual estavam inseridos, graças à conquista do capital econômico. Assim, a intenção dos colégios católicos era justamente oferecer o capital cultural que possibilitasse a essas camadas não apenas ampliar o seu universo de ação profissional, mas, sobretudo, mover-se com desenvoltura num espaço econômico e social que

40 BACZKO, Bronislau. Imaginação social. In: Enciclopédia Einaudi. Lisboa: Imprensa Nacional; Casa da Moeda, 1995. p. 309.

41 A idéia de que a identidade resulta de uma construção social que existe sempre em relação a uma outra também é defendida pelo etnólogo Denys Cuche, que analisa os grupos étnicos vendo a identidade "como uma modalidade de categorização da distinção nós/eles, baseada na diferença cultural". Nessa perspectiva, identidade e alteridade constituem uma relação dialética, ligadas ao processo de inclusão e exclusão. (CUCHE, Denys. A noção de cultura nas ciências sociais. Bauru: Edusc, 1999. p. 175-202) 
exigia cada vez mais o domínio de códigos comuns e o controle de si. Assim, o papel dos colégios católicos era o de criar no jovem um padrão comum de comportamento, por meio de códigos de conduta, que fizessem a mediação entre as práticas individuais, adquiridas pelos alunos no âmbito da família, e a estrutura social. Se, como diz Hobsbawm, as atividades formais desenvolvidas na escola já cumprem esse papel, os colégios católicos foram além, procurando utilizar os espaços de sociabilidade para complementar a interiorização dos códigos e as relações de interdependência, utilizando a juventude como metáfora das permanências sociais. 